\title{
Elliott Sober: Did Darwin Write the Origin Backwards? Philosophical Essays on Darwin's Theory
}

\author{
Prometheus Books, Amherst, NY, 2011, 230 pp, \\ ISBN 978-1-61614-230-8
}

\author{
Raphael Scholl
}

Received: 7 February 2012/ Accepted: 13 February 2012/Published online: 7 April 2012

(C) Springer Science+Business Media B.V. 2012

Did Darwin write the Origin backwards? This is the title and initial question of a new book by Elliott Sober, who joins topics from current philosophy of biology with the historical analysis of Charles Darwin's writings. Since good history and good philosophy of science often walk hand in hand, Sober's approach is highly welcome.

The book has four chapters and three long postscripts, which amount to a fifth chapter. I will discuss them in order.

The first chapter is based on a recent Darwin-year paper (Sober 2009). Sober considers the question of why Darwin, in the Origin of Species (1859), presented natural selection first and common descent second. The choice is not at all obvious. Darwin intended to convince readers first and foremost of the factuality of evolution; that is, of descent with modification. As Sober points out, this is logically independent of the mechanism of modification: A population may be subject to natural selection without branching, and branching may occur in the absence of natural selection. In a letter to Asa Gray from 1863, which Sober quotes, Darwin stated explicitly that the fact of evolution was more important than natural selection. ${ }^{1}$ What is more, I would argue that the Origin was heavy on evidence for common descent, while the case for natural selection was, strictly by comparison, weaker. In part because of this, common descent was widely accepted by the time of Darwin's death in 1882, while the same could not be said for natural selection until the Modern Synthesis of the twentieth century. So why did Darwin not establish the fact of evolution first, by the force of overwhelming evidence, and then discuss possible mechanisms of transformation? Did he write the book backwards?

1 This is letter 4153 in the Darwin Correspondence Project, dated May 11, 1863.

R. Scholl $(\bowtie)$

History and Philosophy of Science, Institute of Philosophy, University of Bern,

Länggassstr. 49a, 3012 Bern, Switzerland

e-mail: raphael.scholl@philo.unibe.ch 
Sober develops a twofold answer. He distinguishes between the causal and evidential ordering of Darwin's theory. Darwin believed that natural selectionconjoined with the "principle of divergence"-produces the branching pattern of common descent. So while natural selection and common descent are logically independent, Darwin believed the former to be a cause of the latter. Therefore, Sober argues, Darwin's presentation is in the right causal order. But Sober then identifies an evidential asymmetry between common descent and natural selection. He argues that we judge hypotheses about descent by looking at traits that are not adaptations. For instance, the shared aquadynamic shape of dolphins and sharks is no indication of common ancestry, since it is an adaptation to life in water. Whether a trait is an adaptation or not can presumably be settled irrespective of whether one considers natural selection to be the mechanism that produces adaptations. Thus, common ancestry can be investigated independently of hypotheses about natural selection. Sober argues that the converse does not hold true: When we judge hypotheses about natural selection, genealogical relationships are useful background knowledge. For instance, when we ask whether skull sutures evolved as an adaptation to live birth, it helps to know what came first - sutures or live birth (as it turns out, the sutures came first, and the selective hypothesis is wrong). So there is an evidential asymmetry between common descent and natural selection, which would ask for common descent to be introduced first. In evidential terms, Sober concludes, the Origin is indeed written backwards. Darwin, however, gave priority to his theory's causal order.

The first chapter is highly readable and will serve to direct readers to Sober's earlier work on the confirmation of natural selection and common descent (Sober 2008). But the arguments concerning Darwin's chosen order of presentation in the Origin are not entirely successful. For one thing, I am skeptical about the significance of the evidential asymmetry between selection and descent. Sober is right in arguing that an asymmetry exists: Historical information is ultimately needed in the evaluation of adaptive hypotheses. But there is much that biologists can learn about adaptive hypotheses by non-historical methods, such as studies of a trait's variability, its heritability and its contribution to fitness. As Sober acknowledges briefly in his discussion of Darwin's Malthusian argument (pp. 43-44), Darwin certainly argued along such lines in the early chapters of the Origin. So it seems to me that the evidential asymmetry is not as pronounced as Sober makes it out to be. Moreover, Sober presents no evidence that the asymmetry played much of a role in Darwin's decision to structure the Origin as he did.

This leads me to my second, deeper concern. Sober is explicit about the fact that he is asking a historical question (see the discussion beginning on p. 32): Why did Darwin, the historical person, actually decide to present selection first and common descent second? Darwin scholars have given convincing answers to this question, and Sober offers few reasons to reject them.

The Origin's structure is usually explained by reference to Darwin's view of how good science works. He held a Herschelian ideal, according to which true causes (verae causae) are demonstrated in three steps. ${ }^{2}$ First, a cause's real existence has to

\footnotetext{
$\overline{2}$ An overview of this literature is given by Waters (2003).
} 
be established. Next, it must be shown that the cause is competent to produce the effects which it is supposed to explain. Finally, it must be shown that in the case at hand, the cause was actually responsible for producing the effect. This fits nicely with Darwin's argument in the Origin. He first establishes artificial selection as an existing and competent cause by discussing selection by breeders. He then goes on to make the analogous case for the existence and competence of natural selection (via Malthus and superfecundity). Finally, he argues for natural selection's responsibility for existing biological diversity.

Sober believes that the Herschelian approach could have been pursued without giving natural selection priority (p. 33). Darwin could have started with readily documented cases of common ancestry in humans and artificial breeding. He would then have extrapolated to conjectured cases of common ancestry, and finally to the claim that all life goes back to a single origin. We know, however, that Darwin would not have considered this a viable argumentative strategy. He explained his thinking on the matter at least twice, and I see little reason not to take his statements at face value. In his autobiography, Darwin noted some of the facts which had steered him toward the hypothesis of common descent, such as the fossils of South America and the fauna of the Galapagos:

It was evident that such facts as these, as well as many others, could be explained on the supposition that species gradually become modified; and the subject haunted me. But it was equally evident that neither the action of the surrounding conditions, nor the will of the organisms (especially in the case of plants), could account for the innumerable cases in which organisms of every kind are beautifully adapted to their habits of life [...] I had always been much struck by such adaptations, and until these could be explained it seemed to me almost useless to endeavour to prove by indirect evidence that species have been modified. ${ }^{3}$

Darwin felt that his evidence for common descent was unpersuasive in the absence of a plausible mechanism of both transformation and adaptation-and thus natural selection needed to be established first. He advanced the same considerations in the introduction to the Origin, where he wrote that common descent, "even if well founded, would be unsatisfactory, until it could be shown how the innumerable species inhabiting this world have been modified, so as to acquire that perfection of structure and coadaptation which most justly excites our admiration" (p. 3). Darwin contrasted his views with those of the author of the infamous Vestiges of Creation, who "would, I presume, say that, after a certain unknown number of generations, some bird had given birth to a woodpecker, and some plant to the misseltoe, and that these had been produced perfect as we now see them; but this assumption seems to me to be no explanation" (pp. 3-4). I do not wish to hoist upon Darwin the notion of "no explanation without mechanism". But something like that notion is in play here, and it coheres with the Herschelian approach. ${ }^{4}$

\footnotetext{
3 Barlow (1958), pp. 118-119.

4 Of course, many of Darwin's readers embraced common descent but rejected natural selection. Did Darwin underestimate the independent strength of his arguments for common descent? Perhaps. But it
} 
All in all, Sober's first chapter is something of an uneasy construction: The philosophy is stimulating, but the historical material is less successful.

The excellent second chapter deals with the levels of selection problem, beginning with an exposition of George C. Williams's conceptual and empirical arguments against group selection. Sober then discusses his own views on group selection, arguing that Williams's objections were misguided, and that group selection can be an effective process in evolution.

The discussion of group selection will again serve to introduce and guide readers to Sober's earlier work on the problem (Sober and Wilson 1999). But the chapter is also an insightful discussion of group selection in its own right. What is more, Sober presents a cogent analysis of Darwin's thinking on the subject in the Origin and The Descent of Man (1871). This is a notoriously difficult subject, and as Sober notes in his text, the consensus has been that Darwin was to a greater or lesser extent confused. Sober argues convincingly that Darwin's position was more subtle than is generally acknowledged. In this instance, the history and the philosophy go well together.

The third chapter is about sex ratio theory. Why do many species have an even sex ratio, and how do other ratios come about? In the course of the chapter, Sober pursues three projects. First, Sober returns to the question of hypothesis testing. He begins with an eighteenth-century-debate about whether sex ratios permit an inference to Divine Providence. Sober discusses probabilistic modus tollens, the Law of Likelihoods (already introduced in the first chapter) and, briefly, Bayes' theorem. Second, Sober provides an analysis of Darwin's writings about sex ratios. In particular, there is the odd fact that Darwin included a section on sex ratios in the first edition of The Descent of Man but then withdrew it in subsequent editions. Sober's interpretation of Darwin's thinking is very plausible. Here again, the history and the philosophy are in harmony. Third, Sober uses sex ratio theory as a test case in the debate between creationism and evolutionary biology. The story moves into the twentieth century and to R. A. Fisher and John D. Hamilton, who laid the foundations for our present understanding of sex ratio evolution. Sober contrasts the specificity of evolutionary models with creationism's general claim that "this was God's will", which can of course be appended to any factual finding but provides no insight.

If the second and third chapters have a shortcoming, it is that their target audience is sometimes unclear. Some passages are introductory in tone, but others seem to be directed at those who are familiar with the debates. In the second chapter, for instance, the example of the $t$-allele (Lewontin and Dunn 1960) is discussed at some length in the main text, but it is only explained in the endnotes. Similarly, the introduction and conclusion of the third chapter seem to address casual readers with an interest in the empirical confirmation of evolutionary theory and the debate with creationism. However, Bayes' theorem is used without much explanation, which suggests that Sober is talking to the initiated, and the sections on Fisher's and Hamilton's work are also quite technical.

Footnote 4 continued

would be wrong to think that those who rejected natural selection did not have mechanistic convictions of their own. For instance, the inheritance of acquired characters and orthogenetic evolution were live alternatives (Bowler 1988). 
The fourth chapter says more about the relationship between science and the supernatural. It can be summarized as Sober's guide to the pitfalls of methodological naturalism. He defines this as the statement that scientific theories, evidence and arguments "should not make claims about the existence of a supernatural deity" (p. 129). (Note that this leaves open the beliefs of individual scientists.) Sober discusses five pitfalls: First, to think that Darwin eschewed theological arguments in the Origin and was a strict methodological naturalist; second, to believe that modern evolutionary theory precludes the operation of supernatural causes; third, to claim that science should only talk about what exists in nature; fourth, to argue that no statements about the supernatural are testable; and fifth, to claim that the supernatural is a "science stopper".

Sober's points are apposite and should be of interest to all who discuss the relationship between science and religion. However, not all of Sober's arguments are equally compelling. For example, on the third point (science should only talk about what exists in nature), Sober argues that science already incorporates "supernatural" entities. He claims that this is so because mathematics is indispensable to science but is not empirical, and therefore must be regarded as supernatural (p. 140). Even to those who sympathize with platonism with regard to mathematical entities, it probably appears hasty to equate "not empirical" with "supernatural". And more deflationary accounts of the role of mathematics in empirical science would leave the argument without traction.

Assuming we can successfully avoid the pitfalls mentioned above, what is the right way to justify and apply methodological naturalism? Sober's pragmatic advice is "if it isn't broken, don't fix it" (p. 148). His preferred strategy is to argue for the superiority of naturalistic to theistic explanations without resorting to any sort of "demarcation criterion" like methodological naturalism. To illustrate this, Sober refers back to the discussion of sex ratio theory in the third chapter. But it is far from clear-to the philosopher of science, in any case-what makes the explanations provided by sex ratio theory good, although Sober discusses various possibilities (see pp. 115-119 and pp. 147-150). Is it the fact that sex ratio theory makes specific predictions (or at least, gives specific explanations), while creationism can in principle accommodate any facts whatsoever? Is it the empirical testability of the sex ratio theory? Or that supernatural add-ons to scientific theories tend to be idle? Or is it even the progress of naturalistic approaches over the past centuries (a sort of Lakatosian approach)? A combination of all four? It is obvious how these questions could lead us right back into the old debates about demarcation, and it would be interesting to see more clearly how Sober intends to navigate the territory.

The fifth and final chapter of the book consists of three postscripts: one on cladistic parsimony; one on conventionalism and realism in the levels of selection debate; and one on the objectivity of macroprobabilities, especially in evolutionary theory. These postscripts are somewhat incongruous since their relationship to the rest of the book is unclear. Nevertheless, they are among the most enjoyable sections of the book, with Sober forcefully laying out a series of purely philosophical arguments. I would recommend especially the postscript on conventionalism and the levels of selection. 
In summary, Sober's new book is attractive and will serve different audiences in different ways. Its ideal readers are probably those who have read and enjoyed Sober's work in the past and have been thinking about returning to his writings. To them, the book is easy to recommend, despite my misgivings about the first chapter's historical component. The historical material in the second and third chapters will appeal particularly to those who are involved or interested in Darwin scholarship. The fourth chapter on methodological naturalism deserves to be widely debated, and the postscripts will be of particular interest to professional philosophers of biology. For casual readers, Sober's pace may be a little too brisk at times, especially in chapters two and three. Nevertheless, I can well imagine this book serving as a gateway to Sober's earlier work.

A bibliophile's postscript is in order. I have worked with both the paperback and the Kindle editions of the book. ${ }^{5}$ The typography and proof-reading of the electronic version are appallingly poor. Words that present any level of typographical difficulty ("naïveté") are mangled; spaces and question marks are missing; parentheses are not closed; and frequently, spaces are inserted where words are hyphenated in the print edition. Such issues should be as unacceptable in e-books as they are in traditional books.

\section{References}

Barlow N (1958) The autobiography of Charles Darwin, 1809-1882. Collins, London Bowler PJ (1988) The non-darwinian revolution. Johns Hopkins University Press, Baltimore Darwin C (1859) The origin of species. John Murray, London

Darwin C (1871) The descent of man, and selection in relation to sex. John Murray, London

Lewontin RC, Dunn LC (1960) The evolutionary dynamics of a polymorphism in the house mouse. Genetics 45:705-722

Sober E (2008) Evidence and evolution: the logic behind the science. Cambridge University Press, Cambridge

Sober E (2009) Did Darwin write the origin backwards? Proc Natl Acad Sci 106:10048-10055

Sober E, Wilson DS (1999) Unto others: the evolution and psychology of unselfish behavior. Harvard University Press, Cambridge (MA)

Waters CK (2003) The arguments in the origin of species. In: Hodge J, Radick G (eds) The Cambridge companion to Darwin. Cambridge University Press, Cambridge, pp 116-139

\footnotetext{
5 The electronic version was downloaded from Amazon.com in December 2011.
} 